\title{
Mental Health and Life Events of Overseas Children Left-Behind in China
}

\author{
Shengyu Zhao', Chuanjing Liao ${ }^{2,3 *}$ \\ ${ }^{1}$ Department of Common Education, Wenzhou Vocational and Technical College, Wenzhou, China \\ ${ }^{2}$ Pedagogy Postdoctoral Research Station, Soochow University, Soochow, China \\ ${ }^{3}$ Department of Mental Health Education, Wenzhou University, Wenzhou, China \\ Email: *cjliao@wzu.edu.cn
}

How to cite this paper: Zhao, S. Y., \& Liao, C. J. (2016). Mental Health and Life Events of Overseas Children Left-Behind in China. Psychology, 7, 1934-1946.

http://dx.doi.org/10.4236/psych.2016.714176

Received: October 15, 2016

Accepted: December 24, 2016

Published: December 27, 2016

Copyright $\odot 2016$ by authors and Scientific Research Publishing Inc. This work is licensed under the Creative Commons Attribution International License (CC BY 4.0).

http://creativecommons.org/licenses/by/4.0/

\begin{abstract}
This paper surveys 715 children who have been left behind in China by their émigré parents. This research was conducted using the MMHI-60, ALSEC and S-I questionnaire and the findings are as follows: 1) the general mental health of those surveyed was poor, with general stress levels and sense of security moderate; 2) there is a positive correlation between life events and mental health and a negative correlation between life events and sense of security; 3) sense of security regulates life events and mental health; 4) life events directly predict mental health, with sense of security playing partial mediating effect in the process of life events acting on mental health; 5) the major factor influencing the mental health of those children left behind by Chinese émigré parents is life events; the protecting factor being their sense of security.
\end{abstract}

\section{Keywords}

Overseas Chinese, Children Left-Behind Children, Life-Events, Sense of Security, Mental Health

\section{Introduction}

China has a long tradition of overseas Chinese who leave their home villages and towns in order to establish and run businesses abroad, often settling down in the host country that offers the best opportunities. However, since most of these migrants are not of a high social status, they have to leave their children behind at home, which leads to the creation of unique communities of children left behind in China by their parents. It is reported that there is a school, known as the "UN school" in Qingtian county of Zhejiang province, an area renown for overseas Chinese the famous overseas Chinese 
county. Of this school's total intake, $70 \%$ are children who have been left behind by parents working abroad. With the parents of these children working and living in 38 different countries around the world ( $\mathrm{Wu}, 2007)$, this is a situation that is replicated in villages and towns across China.

Due to the absence of parents, the children of those left behind by overseas Chinese receive less emotional and educational support than their peers-as Pan et al. (2010) have pointed out, the educational resources that these children's families can provide the mare considerably scarcer than those provided to children living with their parents. Additionally, besides the lack of academic support, these children are deprived the supportive family atmosphere experienced by many of their peers and as such, are deprived of regular parental love and affection. Although they may enjoy better financial conditions than their peers, these children have less communication with their parents, their lives are more formalized (He, 2008) and in their mind, there is the constant and strong yearning for greater emotional contact with their parents, which often leads to a desire to follow their parents aboard, where they can live as a family. These children are often taken care of by grandparents or other relatives and are regularly required solving many of life's problems alone, suffering more stress from these life events as a consequence. Life events are a common source of mental and social stress, and an major source of depression, anxiety etc. (Nadia \& Vivian, 2006), and an excessive amount of negative pressure resulting from such events can lead to physical and mental health problems (Niemi \& Vainiomaki, 1999), the lowering of personal self-esteem (Silver \& Glicken, 1990), with academic and personal development also being affected (Kaplan \& Saddock, 2000). At present, however, there is a considerable lack of empirical research into the effects of life events on the children left behind by parents living overseas.

Growing up in this particularly family environment and influenced by life events, many of the children left behind by overseas Chinese display various cognitive deviations in life, study and interpersonal communication, such as an increased sensitivity to interpersonal communication, feelings of anxiety about current and future life plans and a lack of confidence in themselves which inevitably has a negative impact on their physical and mental health.

Many of these problems are rooted in their lack of a sense of security, which, as a most fundamental psychological need, is the assessment of potential danger or risk and manifested as the degree of certainty and control one feels when dealing with stress (An \& Cong, 2003). Possessing a sense of security means that one experiences a diminished sense of threat from physical or emotional harm, guaranteeing security and stability in a chaotic world, free from fear (Maslow, Hirsh, Stein, \& Honigmann, 1945). Melanie (2011) argues that a sense of security is a kind of mental resource, which provides people with the means to improve information processing competence and mediate stimulus and response, helping them to mobilize social support systems and gain a greater sense of happiness from doing so. Yet for the children of overseas Chinese, can their sense of security also moderate the impact of life events on their own mental health? And can we improve their mental health by increasing their sense of security? 
In addressing these questions, this research aims to reveal some of the key physical and mental developmental characteristics of this particular group and provide empirical evidence to suggest that they should be supported with the provision of adequate and appropriate mental health education.

\section{Methods}

\subsection{Participants}

The children left behind by overseas Chinese discussed in this paper are children aged between 9 and 16, from families with either one or both of their parents working abroad and who have been separated from their parents for a period which surpasses 6 months. Children were selected as study subjects according to this set of criteria from Qingtian county, Wencheng county, Ruian county and Ouhai county by means of purpose sampling and random cluster sampling. 800 copies of a questionnaire were handed out, 771 retrieved and 715 of which are valid, the rate of validity being $92.47 \%$. The age of samples is $13.05 \pm 1.21$ and the detailed distribution is as follows: boys 340 (47.6\%), girls 375 (52.4\%); only child 230 (32.2\%), not only child 485 (67.8\%); grade 5 children 176 (24.6\%), grade 6 children 173 (24.2\%), grade 7 children 194 (27.1\%), grade 8 children 172 (24.1\%); both parents abroad 607 (84.9\%), one parent abroad 108 (15.1\%).

\subsection{Measures}

\subsubsection{Adolescent Self-Rating Life Events Checklist (ASLEC)}

The measure has 27 questions including interpersonal relationships, pressures on learning, punishment, loss, health adaptation and other causes of stress. These factors, six in total, are used to measure the frequency and intensity of stress experienced by adolescents, especially students from middle schools and colleges. The higher the score is, the greater the impact of life events. Correlation coefficients between each life event score and the total score range from 0.24 to 0.57 , with an average score of 0.45 and Cronbach's alpha 0.85 (Wang, Wang, \& Ma, 1999). The alpha for the measure in this study is 0.815 .

\subsubsection{Middle-School-Students Mental Health Inventory (MMHI-60)}

The measure is compiled by Wang et al. (1997), comprising of 60 questions and 10 scales, with each scale comprising 10 questions. The 10 scales are obsession, stubbornness, hostility, interpersonal sensitivity, depression, anxiety, pressures of learning, mal-adaptation, emotional instability and psychological imbalance. The inventory uses Likert's 5-point scoring method, 1 - 5 points signifies respectively the situation of never, mild, moderate, a little serious and very serious. The higher the total and individual scale scores are, the greater the problems of the respondents' mental health. The homogeneity reliability of the scales is between 0.65 and 0.86 , with split-half reliability between 0.63 and 0.87 . The alpha for the inventory in this study is 0.933 .

\subsubsection{Security and Insecurity Questionnaire (S-I)}

Cao revised Maslow's 75-question long Security and Insecurity questionnaire. The re- 
vised questionnaire has 44 questions, with the 3 factors being emotional security, interpersonal security and self-security. The questionnaire adopts "yes", "no" and "not clear" as its three scales of scoring. The higher the total score, the higher the sense of security (Wang, 2011). The alpha of this measure in this study is 0.785 .

\subsection{Procedure}

The 800 participates in the study were randomly determined from the primary and secondly schools in Zhejiang Province, China. Self-report measures were administered to students in the classroom environment by researcher. Participation was voluntary and prior to completing the measures, informed consent was obtained from all participants. Children left behind did not place their names on the measures and were assured of the confidentiality of their responses. The participates were encouraged to keep their answers confidential and not to talk with classmates about their answers. The completion of the measures took approximately 30 minutes and at the end of the study, we sent a small gift of RMB 10 (approximately US\$ 1.65) to each participant to show our gratitude.

\subsection{Ethical Considerations}

Because all of the participants in research were under the age of 18 , we needed to address seriously the ethical considerations. Informed consent from parents or guardians as well as consent from the children left behind themselves was obtained, after the purpose and method of this study were explained to them. In addition, they were assured that their responses would be confidential and that their identities would not be revealed.

\subsection{Data Processing}

Descriptive statistics were used to examine the characteristics of sample, including frequency and percent for gender, age and grade etc., and means and standard deviations (SDs) for mental health, life events and sense of security. In order to examine the correlations between the life events and mental health \& sense of security of overseas Chinese children left behind, Pearson analysis process was conducted. In order to test the regulating effect of sense of security on life events and mental health, a step line regulation process was conducted. Lastly, in order to further demonstrate whether the mediating effect of the sense of security between the life events and mental health, the Amos data analysis process was used. Data were analyzed using SPSS version 20.0 and Amos 20.0.

\section{Results}

\subsection{The General Situation with Regard to Mental Health, Life Events and Sense of Security of Those Children Left Behind by Overseas Chinese}

Survey results show that the gross average score of children left behind by parents 
working overseas in the sphere of mental health is $1.93 \pm 0.51$, which is strikingly higher than the norm $(\mathrm{n}=2466)$ [12] $(\mathrm{t}=2.575, p=0.010)$. Factors in the sphere of mental health whose scores exceed the norm are listed as follows: anxiety $(2.15 \pm 0.76 ; \mathrm{t}=$ $12.072, p<0.001)$ sense of learning pressure $(2.21 \pm 0.80 ; \mathrm{t}=9.4764, p<0.001)$, emotional instability $(2.19 \pm 0.66 ; \mathrm{t}=8.568, p=0.008)$, interpersonal sensitivity ( $1.95 \pm$ $0.64 ; \mathrm{t}=4.027, p<0.001)$, obsession (1.98 $\pm 0.59 ; \mathrm{t}=3.957, p<0.001)$ and stubbornness $(1.82 \pm 0.63 ; \mathrm{t}=2.404, p=0.016)$; those that are strikingly lower than the norm are psychological imbalance $(1.57 \pm 0.48 ; \mathrm{t}=-21.628, p<0.001)$ and mal-adaptation $(1.82$ $\pm 0.57 ; \mathrm{t}=-4.787, p<0.001)$; Those that are not strikingly different from the norm are hostility $(1.71 \pm 0.66 ; \mathrm{t}=-0.298, p=0.765)$ and depression $(1.90 \pm 0.62 ; \mathrm{t}=-0.828, p=$ $0.408)$.

The gross average impact of life events on the children left behind by overseas parents is $1.72 \pm 0.43$ and the detection rates of all factors are listed from high to low as follows: health adaptation $(60.56 \%, 1.83 \pm 0.56)$, loss $(54.55 \%, 1.53 \pm 0.76)$, learning pressure $(49.23 \%, 2.13 \pm 0.65)$, interpersonal relations $(23.22 \%, 1.92 \pm 0.62)$, punishment $(22.52 \%, 1.37 \pm 0.43)$ other causes of stress $(19.16 \%, 1.55 \pm 0.60)$. Gross average score of sense of security is $0.63 \pm 0.22$, factors from high to low are: Interpersonal security $(0.73 \pm 0.22)$, emotional security $(0.57 \pm 0.26)$ and self security $(0.53 \pm 0.31)$.

\subsection{Correlations between Life Events and Mental Health \& Sense of Security of Overseas Chinese Children Left Behind}

Correlation analysis shows that the life events gross average score of these children's life events and each factor's score correlate significantly with that of the mental health. The correlation coefficient between life events average score and that of mental health is 0.668, while life events have a significant negative correlation with sense of security (See Table 1).

\subsection{Sense of Security Arbitrates Life Events and Mental Health of Those Children Left Behind by Overseas Chinese}

For those left-behind children, whether or not the impact of life events on their mental health is mediated by a sense of security (regulating effect) remains an idea waiting further testing. Hypothesis: in the space between life events and mental health, sense of security has a regulating effect (See Figure 1).

According to the procedure proposed by Baron \& Kenny (1986) and Wen, Hou, \& Zhang (2005), testing the regulating effect of sense of security can be done by following the steps below: 1) Centralizing the scores for life events and sense of security 2) Generating and taking "life events $\times$ sense of security" as the interactive term. 3) Taking mental health as a dependent variable and applying hierarchical regression analysis, the first step of which is to introduce the main effect term, 'life events and sense of security'; the second step is to introduce the interactive term 'life events $\mathrm{x}$ sense of security' by testing the significance of the newly added quantity $\left(\Delta R^{2}\right)$ or regression coefficient of the interactive term and estimating whether the regulating effect of sense of security is significant (See results in Table 2). 
Table 1. Correlation between life events and sense of security, mental health of those children left behind by overseas Chinese.

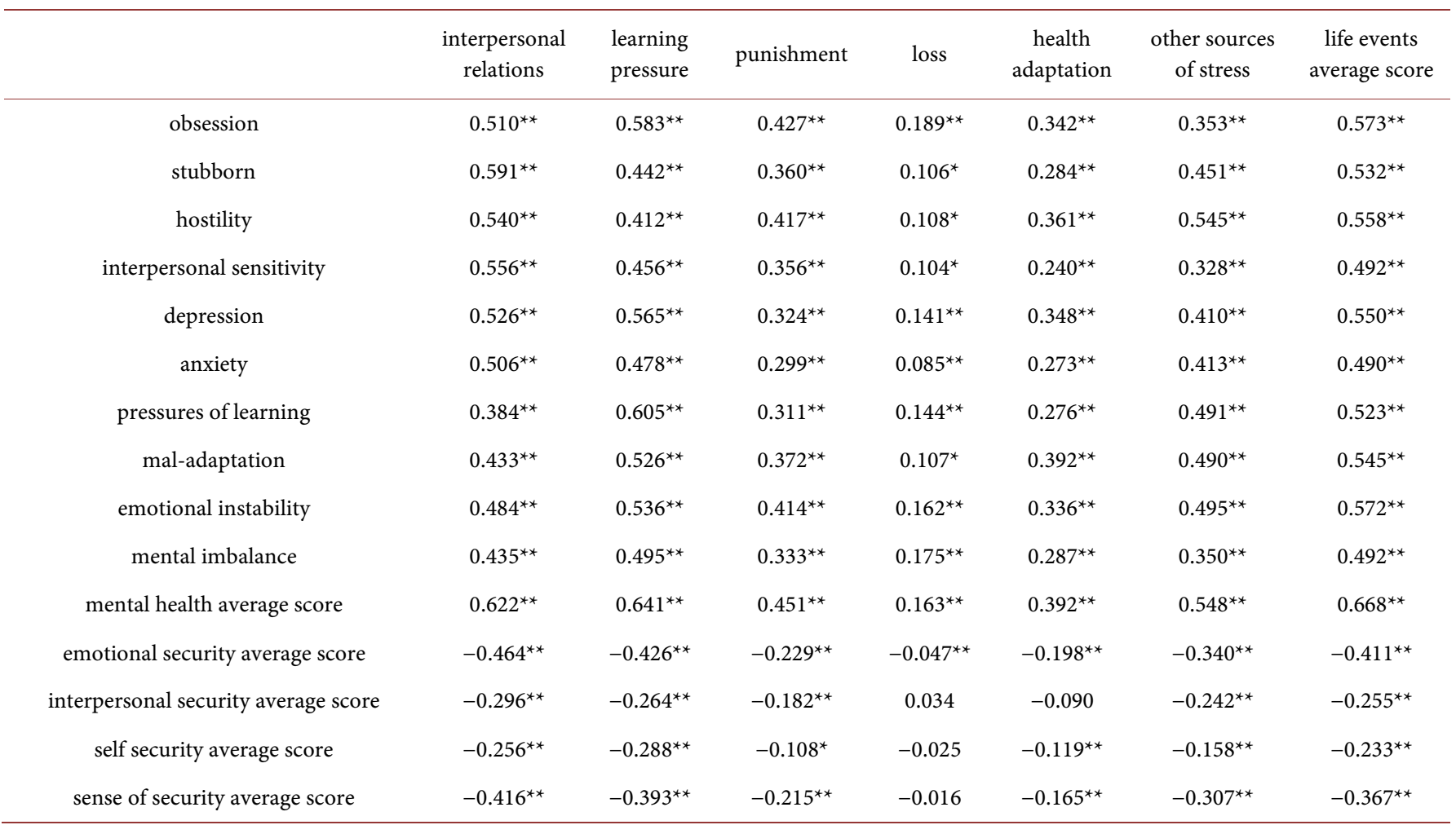

Note. ${ }^{*} p<0.05,{ }^{* *} p<0.01$ (similar hereinafter).

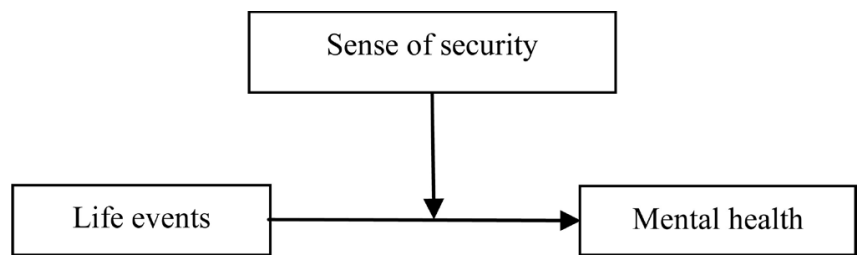

Figure 1. The regulating effect of sense of security.

Table 2. Sense of security's regulating effect on life events and mental health.

\begin{tabular}{|c|c|c|c|c|c|}
\hline steps & Independent variable & $\beta$ & $t$ & $\Delta R^{2}$ & $\Delta F$ \\
\hline 1 & Sense of security & -0.484 & $-20.302^{\star *}$ & 0.209 & $431.792^{\star \star}$ \\
\hline 2 & Life events $\times$ sense of security & -0.051 & $-2.282^{*}$ & 0.003 & $5.206^{*}$ \\
\hline
\end{tabular}

The regression coefficient of the interactive term, "life events $\times$ sense of security" in the regression equation, in which mental health is the dependent variable, achieves significance. After the interactive term is introduced, the newly added explanation quantity achieves significance too, that is, after the interactive term "life events $\times$ sense of security" is introduced, the explanation quantity for mental health increases strikingly, indicating that sense of security has a significant regulating affect on the process of life events affecting mental health; to summarize, the data gathered through research backs 
the hypothesis that sense of security has a regulating effect.

\subsection{Mediating Effect of Sense of Security on Life Events and the Mental Health of Children Left-Behind by Overseas Chinese}

In order to further demonstrate whether the life events of left-behind children influence their mental health through affecting their sense of security (mediating effect), the study verifies the appropriateness of fitting of data and hypothesized model by means of SEM, and obtains the SEM of mediating effect on the left-behind children (See Figure 2). The specified fitting indexes are: $x^{2}=671.934, d f=143, x^{2} / \mathrm{d} f=4.731, R M S E A=$ 0.079, $G F I=0.883, A G F I=0.840, N F I=0.895, C F I=0.914, I F I=0.915$.

All the fitting indexes in the model meet the requirements of metrology; the model's fitting is good. Path analysis shows that after a sense of security is introduced, life events still have a strikingly direct predicting effect on mental health (0.51). Meanwhile, life events have an indirect predicting effect (0.27) on mental health by affecting sense of security, which shows that sense of security has a partial mediating effect between life events and mental health. The proportion of this mediating effect on sense of security in life events affecting mental health is $34.62 \%$.

\section{Discussions}

\subsection{General Situation of Mental Health, Life Events and Sense of Security for Overseas Chinese Children Left Behind}

Similar to many other study results, the state of the mental health of many overseas

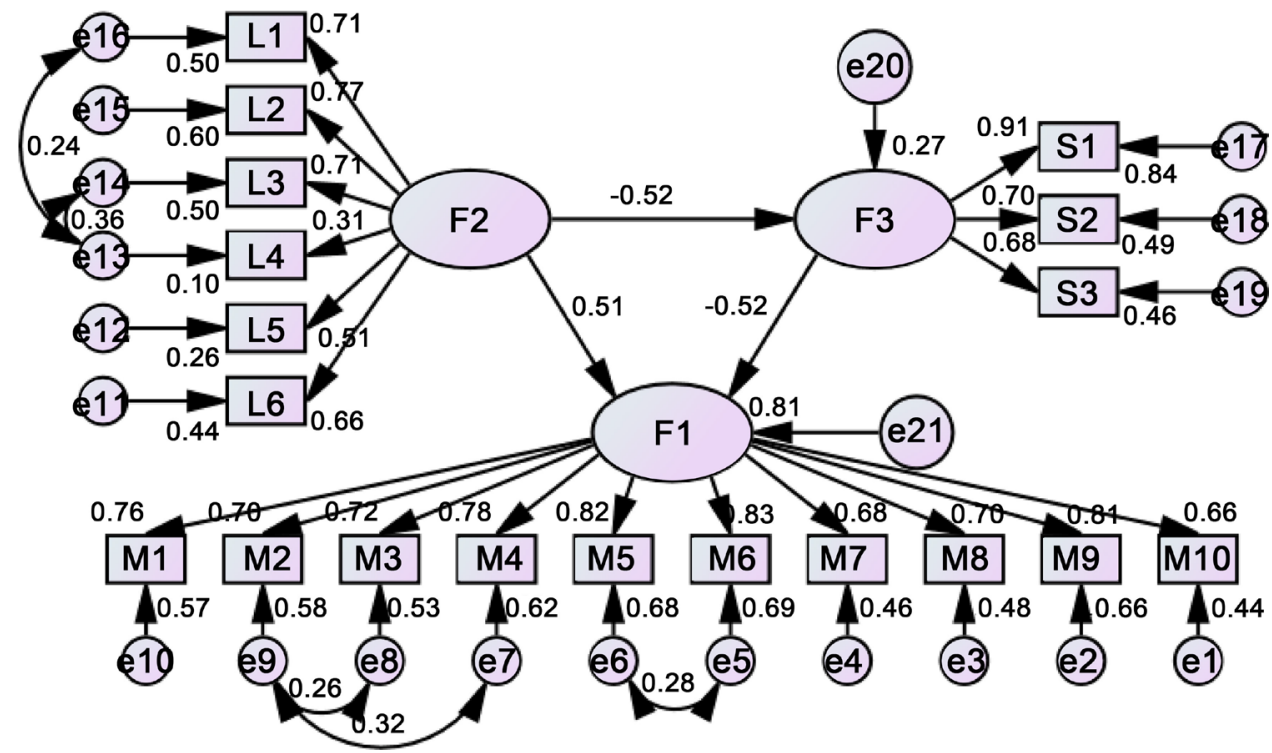

Remark: F1 mental health, F2 life events, F3 sense of security; M1 obsession, M2 stubbornness, M3 hostility, M4 interpersonal sensitivity, M5 depression, M6 anxiety, M7 sense of learning pressure, M8 mal-adaptation, M9 emotional instability, M10 mental imbalance; LI interpersonal relations, L2 learning pressure, punishment, L3 loss, L4 health adjustment, L5 other stress react; S1 emotional security, S2 interpersonal security, S3 self security.

Figure 2. Sense of security's mediating effect. 
Chinese children who are left behind is strikingly poorer than the average, which demonstrates that the mental health of these children face great challenges. These general mental problems occur due to a lack of parental education, care and communication, as well as the dislocation of these children's school education. The symptoms are as follows: feelings of anxiety about the future and their daily reality, a failure to realize the connection between learning and personal prospects. As a result, negative emotions like impulsiveness, anger, and revenge often occur, including sensitivity when conducting interpersonal communication, difficulty in setting up stable interpersonal ties, obsessive behavior and rigid and inflexible opinions and emotions about society, school and others, are also often observed. Meanwhile, the polarized social-cultural environment of the hometowns in which these children live provide a further negative effect on their physical and mental health, their daily life contrasting with the times when their parents visit home, bringing with them not just abundant material wealth but western ideas, value systems and improper lifestyles. This can harm the physical and mental health of their children, confusing their ability to understand the world and skewing their perceptions of material wealth, over time leading them towards a path of epicurean indulgence and decadence. To conclude, without the proper education and guide from family, school and society, superior material conditions can actually be harmful for the development of these children. This conclusion not only applies to overseas Chinese children who are left behind; it is also the case for many other children, and ultimately quite significant for the education of children from both this particular background and other more ordinary families.

The study uncovers this point through empirical analysis with a large sample size. The scale by which the left behind children of overseas Chinese are affected by stresses from life events is moderate in extent; the effects of loss and the pressures of study, as well as on the pressures of adapting to new circumstances are higher in intensity. Since most of the children are far away from their parents, they have to face many problemssuch as the inability to handle school life, teachers' teaching methods and their learning environment-alone, and as such, are unwilling to participate in after class activities, exhibit moodiness etc., which results in intense stress on their mental and physical health. At the same time, their distance from their parents, as well as the duration of the separation, renders them hard to perceive and they struggle to experience warmth and support from other family members, which is a challenge for young, immature children, and manifest itself as the stress of loss.

Furthermore, children from grades five to eight are at a key period in their academic development; however, learning pressure is not the most typical and ordinary life stress experienced by these children, which is closely related to their identity as being left behind. After years of formal school education, these children do become aware that learning is their main task for their personal growth, however, their school grades are generally poor due to the absence of parental supervision, care and guidance, and they thus experience deep anxiety in regard to self identity and self efficacy. Meanwhile, promises from parents of providing a good job abroad during their limited communi- 
cation with their children develop in the majority of these children negative opinions about learning (He, 2008), thinking that they can gain good opportunities abroad without having to study hard. The perception of study as being useless is prevalent, therefore, among groups of children left behind by their overseas parents. As such, it is incumbent upon overseas Chinese that during the limited influence that they are able to exert, they should try best to keep frequent communication with the children, and not concern themselves entirely with their child's learning but instead focus on his or her internal feelings. At the same time, they should try to avoid the possibility of their own words or opinions having a negative effect on their children.

Survey results show that scoring in terms of sense of security for these children rank in the middle and thus there is plenty of room for improvement. Such internal sense of security originates from early stable parent-child attachment and emotional bonds. Individuals that have a strong sense of security have confidence and self-esteem that enables them to set up interpersonal trust, explore personal potential and realize humanity and values adequately. Long-term parent-child separation leads to interpersonal sensitivity, low self-efficacy and decreased emotional control, thus the sense of security of these children has much room for improvement. Parents' care, teachers' guide, society's attention and personal efforts all effectively raise the level of the left-behind children's sense of security.

\subsection{Correlation Analysis between Life Events and the Mental Health of Children Left Behind by Overseas Parents}

The mental health and stress caused by life events as experienced by those children left behind by overseas parents are in striking positive correlation, as verified in the findings made by Bifulco, Bernazzani, Moran, \& Ball (2000) and Franko et al. (2004). The findings demonstrate that the mental health of these children is closely related to stresses from life events such as adaptability to change in environment, experience of loss, learning pressure, interpersonal communication and punishment etc. In other words, the stress of life events on these children is a direct and important external factor that affects their mental health. Comparisons of survey results show that different life events correlate differently to the different aspects of mental health. Stress resulting from interpersonal relations correlates most closely to stubbornness $(r=0.591)$, that can be observed in different aspects of interpersonal communication, such as perception, judgment, comprehension and reaction. The stress of study correlates closest to a sense of learning pressure $(r=0.591)$ and punishment and stress of loss correlate closest to obsession $(r=0.427)$. Frequent and intense punishment of these left-behind children may lead to their propensity towards obsession; stress on ones health resulting from adapting to a changing environment correlates closest to mal-adaptation ( $r=$ 0.427). Other stresses produce more hostility in the children left behind by of overseas Chinese $(r=0.427)$. When we are considering the mental health of these children, special attention should be given to the striking impact of life events.

The interaction between life events and mental health is circulatory and each may be 
the cause of the other; for example, a student's fatigue, difficulties sleeping, anxiety, anger and depression may also affect their life and study (Niemi \& Vainiomäki, 2006). While life events affect mental health, good personalities and social supporting systems can act as a protecting factor of mental health (Friedlander, Reid, Shupak, \& Cribbie, 2007). In this study, sense of security and life events are in significant negative correlation, which shows good psychological qualities of the left-behind children can somehow decrease the influence of life events and ease the life pressure brought by them. Therefore, by introducing mental health education in schools, training students' to develop good personalities, and creating advantageous social supporting systems for students may help them cope with negative life events more effectively.

\subsection{An Analysis of the Regulating and Mediating Effects of Sense of Security on Children Left Behind by Overseas Chinese}

Tests have found that the sense of security of these children plays the role of regulator during the process of life events affecting mental health. The existence of a regulating effect indicates that the cause and effect relationship between the dependent variable and the independent variable changes as the regulating variable is given different values (James \& Brett, 1984). It indicates that the relationship of cause and effect between life events and mental health varies as someone's sense of security differentiate in values; that is, is affected by different levels of sense of security. Sense of security can improve self-identity and help one apply a positive strategy to cope with stress in order to avoid self-destructive behavior and promote self-development (Britton, Phan, Taylor, Welsh, Berridge, \& Liberzon, 2006). People with a strong sense of security have higher self-efficacy and self control and believe they are able to influence their environment (Fagerstro, Gustafon, Jakobsson, Johansson, \& Vartiainen, 2011); on the whole, they feel that the world is safe and that they are able to explore the world with curiosity, confidence, and devotion (Mikulincer \& Shaver, 2007). People with a low sense of security often have high propensity toward self doubt, with a lack of confidence in their own identity and dare not affirm one's basic value. As confidence fades away, they may develop baseless fears and an impatience when conducting interpersonal relations and when faced with new life events (Nowinski, 2001).

In response to stimulus from the outside world, these children have a different level of insecurity and as such, their perceptions, experiences and comprehension of their environment are different from their peers, leading to different types of changes in their mental health. In practice, educators need to train these children to develop a stronger sense of security so that their mental health can be regulated towards positive direction.

Tests of the mediating effect of sense of security reveals that the life events of these children act on mental health by first acting on sense of security and thereby influencing mental health. According to Baron and Kenny, the mediating variable is the intermediate factor and the essential and internal cause by which the independent variable affects the dependent variable (Baron \& Kenny, 1986). The study shows that the sense of security of these children who are left behind produces a partial mediating ef- 
fect in the process of life events affecting mental health. The effect of life events on mental health is significant, frequent, and the events with higher intensity tend to impact the sense of security of these children. Moore argues that events such as parent-children separation induce fear in people, which is probably at the root of the lack of sense of security experienced. Individuals then repeatedly reinforce the fear, which further exacerbates this sense of insecurity (Moore, 2010). In daily life, unexpected happenings, disturbed life routines, being forced to accept changes, make us feel insecure, which coincides with the way life events affect the sense of security of those children left behind. However, people tend to ignore the potential effect of environmental changes on their mental health; it's just the potential process that leads to mental health developing from ordinary symptoms to serious ones. Julia points out, provision of routine, love and honesty by care givers helps to bring a sense of security, reduce children's fear and overcome difficulties (Julia, 2004). It is undoubtedly beneficial to the psychological coaching and mental health counseling which serve the children of overseas Chinese, given their special education circumstances.

Limitations of the study maybe the small amount of the participates, another grades of the subjects should be included. More influential factors such as economic state, vacation of parents of children left behind and the social supports state will be the future directions of the research.

\section{Conclusion}

Through the research detailed above, we draw the following conclusions: 1) The mental health of children left behind by overseas Chinese is worrying; adapting to changes in environment, the experience of loss and study pressure are the major life events which cause stress, with a sense of security remaining moderate, leaving plenty of room for improvement; 2) Their life events are in significant positive correlation with their mental health, and negative correlation with their sense of security. 3) Sense of security has a significant regulating effect in the process by which life events affect the mental health of these children. 4) Life events directly affect mental health and sense of security plays a partial mediating effect. 5) Considering the special educational background of these children, life events are the influential factor in the children's mental health, while a sense of security is the protecting factor; protection of mental health can thus be achieved by improving their sense of security.

\section{Funding}

This study was funded by the 2014 Youth Fund Projects of Humanities and Social Science Research of the Ministry of Education, People's Republic of China (14YJC840017) and by the Center for Chinese Farmers' Development: the Key Research Base of Philosophy and Social Sciences in Zhejiang Province, by the Zhejiang Federation of Humanities and Social Sciences Union (14JDNF03YB). The funders had no role in study design, data collection and analysis, decision to publish, or preparation of the manuscript. 


\section{Competing Interests}

The authors have declared that no competing interests exist.

\section{References}

An, L. J., \& Cong, Z. (2003). Review on Sense of Security Studies. China Behavior Medicine Science, 12, 698-699.

Baron, R. M., \& Kenny, D. A. (1986). The Moderator-Mediator Variable Distinction in Social Psychological Research: Conceptual, Strategic, and Statistical Considerations. Journal of Personality and Social Psychology, 51, 1173-1182. https://doi.org/10.1037/0022-3514.51.6.1173

Bifulco, A., Bernazzani, O., Moran, P. M., \& Ball, C. (2000). Lifetime Stressors and Recurrent Depression: Preliminary Findings of the Adult Life Phase Interview (ALPHI). Social Psychiatry and Psychiatric Epidemiology, 35, 264-275. https://doi.org/10.1007/s001270050238

Britton, J. C., Phan, K. L., Taylor, S. F., Welsh, R. C., Berridge, K. C., \& Liberzon, I. (2006). Neural Correlates of Social and Nonsocial Emotions: An fMRI Study. Neuroimage, 31, 397-409. https://doi.org/10.1016/j.neuroimage.2005.11.027

Fagerstro, M. L., Gustafon, Y., Jakobsson, G., Johansson, S., \& Vartiainen, P. (2011). Sense of Security among People Aged 65 and 75: External and Inner Sources of Security. Journal of Advanced Nursing, 67, 1305-1316. https://doi.org/10.1111/j.1365-2648.2010.05562.x

Franko, D. L., Striegel-Moore, R. H., Brown, K. M., Barton, B. A., McMahon, R. P., Schreiber, G. B., Crawford, P. B., \& Daniels, S. R. (2004). Expanding Our Understanding of the Relationship between Negative Life Events and Depressive Symptoms in Black and White Adolescent Girls. Psychological Medicine, 34, 1319-1330. https://doi.org/10.1017/S0033291704003186

Friedlander, L. J., Reid, G. J., Shupak, N., \& Cribbie, R. (2007). Social Support, Self-Esteem, and Stress as Predictors of Adjustment to University among First-Year Undergraduates. Journal of College Student Development, 48, 259-274. https://doi.org/10.1353/csd.2007.0024

He, Y. (2008). Research Report of Developing Situation of Left-Behind Children at Overseas Chinese Hometown-Taking Qingtian County in Zhejiang Province for Example. China Youth Study, 10, 53-57.

James, L. R., \& Brett, J. M. (1984). Mediators, Moderators, and Tests for Mediation. Journal of Applied Psychology, 69, 307-321. https://doi.org/10.1037/0021-9010.69.2.307

Julia, W. R. (2004). What Children Need When They Grieve: The Four Essentials: Routine, Love, Honesty, and Security. New York: Three Rivers Press.

Kaplan, H. I., \& Saddock, B. J. (2000). Learning Theory in: Sypnosis of Psychiatry. 8th ed. Behavioral Sciences/Clinical Psychiatry. Lippincott Wilkins \& Williams, 148-154.

Maslow, A. H., Hirsh, E., Stein, M., \& Honigmann, I. (1945). A Clinically Derived Test for Measuring Psychological Security-Insecurity. The Journal of General Psychology, 33, 21-41. https://doi.org/10.1080/00221309.1945.10544493

Melanie, C. (2011). What Underlies Security? Neurological Evidence for Attachment's Resource Enhancement Role. Lawrence: Faculty of the University of Kansas.

Mikulincer, M., \& Shaver, P. R. (2007). Attachment in Adulthood: Structure, Dynamics, and Change. New York, NY: Guilford Press.

Moore, B. (2010). So Long, Insecurity. New York: Tyndale House Publishers.

Nadia, G., \& Vivian, K. (2006). Relationships between Cognitive Emotion Regulation Strategies and Depressive Symptoms: A Comparative Study of Five Specific Samples. Personality and Individual Differences, 40, 1659-1669. https://doi.org/10.1016/j.paid.2005.12.009 
Niemi, P. M., \& Vainiomaki, P. T. (1999). Medical Students' Academic Distress, Coping and Achievement Strategies during the Preclinical Years. Teaching and Learning in Medicine, 11, 125-134. https://doi.org/10.1207/S15328015TL110302

Niemi, P. M., \& Vainiomäki, P. T. (2006). Medical Students' Distress-Quality, Continuity and Gender Differences during a Six-Year Medical Programme. Medical Teacher, 28, 136-141. https://doi.org/10.1080/01421590600607088

Nowinski, J. (2001). The Tender Heart: Conquering Your Insecurity. New York: Versailles Press.

Pan, Y. J., Tian, X. X., \& Wang, Y. R. (2010). Relationship of Overseas Chinese Left-Behind Children's Family Education Resources and Personality, Behavior-Taking Wenzhou City as Example. Overseas Chinese History Research, 9, 21-30.

Silver, H. K., \& Glicken, A. D. (1990). Medical Student Abuse: Incidence, Severity, and Significance. Journal of the American Medical Association, 263, 527-532. https://doi.org/10.1001/jama.1990.03440040066030

Wang, J. S., Li, Y., \& He, E. S. (1997). Scaling and Standardization of China Middle School Students' Mental Health. Social Psychological Science, 4, 15-20.

Wang, X. D., Wang, X. L., \& Ma, H. (1999). Handbook Mental Health Assessment Scale (EXpanded Edition). Beijing: Mental Health Magazine, 194-196.

Wang, Y. Z. (2011). The Psychological Rating Scale Manual(1990-2010). Zhengzhou: Zhengzhou University Press.

Wen, Z. L., Hou, J. T., \& Zhang, L. (2005). Comparison and Application of Regulating Effect and Mediating Effect. Acta Psychologica Sinica, 37, 268-274.

Wu, F. F. (2007). Thinking and Current Situation of Qingtian County Overseas Chinese LeftBehind Children. Women's Work, 8, 1-3.

Submit or recommend next manuscript to SCIRP and we will provide best service for you:

Accepting pre-submission inquiries through Email, Facebook, LinkedIn, Twitter, etc. A wide selection of journals (inclusive of 9 subjects, more than 200 journals)

Providing 24-hour high-quality service

User-friendly online submission system

Fair and swift peer-review system

Efficient typesetting and proofreading procedure

Display of the result of downloads and visits, as well as the number of cited articles Maximum dissemination of your research work

Submit your manuscript at: http://papersubmission.scirp.org/

Or contact psych@scirp.org 